\title{
Breaking Barriers for Cerebrospinal Fluid Flow in Chiari Malformation Type I: "What and How Much Is Enough?" A Retrospective Analysis of 74 Cases
}

\author{
Manish Jaiswal ${ }^{1}$ Amit Raj Patil ${ }^{2}$ Radhey Shyam Mittal ${ }^{2}$ \\ ${ }^{1}$ Department of Neurosurgery, King George's Medical University, \\ Lucknow, Uttar Pradesh, India \\ 2Department of Neurosurgery, SMS Medical College and Hospital, \\ Jaipur, Rajasthan, India \\ Indian J Neurosurg 2018;7:196-208
}

Address for correspondence Manish Jaiswal, MCh, Department of Neurosurgery King George's Medical University, Lucknow, Uttar Pradesh, 226003, India (e-mail: manishjaiswal@kgmcindia.edu).

\begin{abstract}
Introduction: Chiari malformation type I is a collection of hindbrain abnormalities, for which natural history of the disease process is not clear. The challenge is to identify which patients will benefit most from posterior fossa decompression.

Objectives: To identify important surgical implications that most likely benefit patients with Chiari malformation type I by analyzing and reviewing various operative interventions in these patients with appropriate symptoms and then following their course.

Subjects \& Methods: Retrospective analysis of 74 operated Chiari malformation type I with syrinx adult patients was done.

Results: No definite pattern of progression in natural history of disease was noted. Most of the patients who were symptomatically stable for months to years presented with recent rapid progression. The most common symptom was suboccipital pain. The most common finding was lower extremity weakness. On clinical presentation basis, patients were divided into three categories: foramen magnum compression syndrome, central cord syndrome, and cerebellar syndrome. Most patients in our study fall in first category. Foramen magnum decompression with atlas posterior arch removal and sometimes partial C2 laminectomy depending on extent of tonsillar descent as well as augmentation duraplasty was done in most patients. Improvement was seen in

Keywords

- Chiari malformation type I

- syrinx

- foramen magnum decompression foramen magnum compression syndrome group more significantly.

Conclusions: Individualized surgical techniques for breaking the barriers of cerebrospinal fluid (CSF) flow in Chiari malformation type I with syrinx to restore normal CSF dynamics across craniocervical junction provide the pragmatic solution. The trend is toward balance between optimum wide decompression as compared with long craniocaudal decompression and preserving normal integrity.
\end{abstract}

\section{Introduction}

Chiari malformation (CM) type I are becoming more commonly faced by neurosurgeons with increased uses of magnetic resonance imaging (MRI). This complex entity is a collection of hindbrain abnormalities having long medical history. Several classic reviews have been attempted

received

June 30, 2018

accepted after revision

September 19, 2018
DOI https://doi.org/

10.1055/s-0038-1676664 ISSN 2277-954X. to clarify a variety of complex associated issues. Despite the volumes of publications on the subject, the literature review shows that the natural history of this disease process has not been established. Abnormal cerebrospinal fluid (CSF) dynamics across craniovertebral junction and frequent spinal cord cavitation are among the prominent facets of disease process.
(C)2018 Neurological Surgeons' Society of India
License terms

(() $\odot \circledast$ 
The clinical examination is crucial in the diagnosis, and the challenge is to identify which patients will benefit most from posterior fossa decompression. Controversy regarding operative intervention continues in patients without a syrinx, and surgical indications may vary among surgeons, especially for subjective symptoms such as headache. Management is further complicated by variability in technical aspects of decompression. In our study, complete surgical experience of 74 patients who were operated upon for adult presentation CM type I with syrinx was retrospectively analyzed. We set out to identify important surgical implications that most likely benefit patients. By analyzing operative intervention in patients with appropriate symptoms and then following their course, we hope to outline the present status of this entity.

\section{Subjects and Methods}

This is a retrospectively analyzed study of 74 patients (mean age: 28.8 years, range: $6-58$ years, 55 males and 19 females) who were managed surgically for adult CM type I from 1998 to 2016. The inclusion criteria were symptomatic patients with appropriate clinical findings and MRI consistent with CM type I. Patients included in this study were followed in postoperative period for at least 18-month duration. Patients in whom another cause was established (trauma, arachnoiditis, and tumor), atlantoaxial dislocation, and those who lost follow-up were excluded from study. Control group consisted of the patients with CM type I in long-term follow-up in outpatient department (OPD) who opted for conservative management. Because of this, statistical comparison was not possible between these two groups.

Pain in the suboccipital or cervical region was the predominating symptom in most patients (56\%). Average duration of symptoms clearly related to CM type I was 4.2 years (range: 2 months to 15 years). In current era of MRI, latency is reduced. The clinical profile of patients is summarized in (-Table 1). The radiologic investigations included MRI craniovertebral junction with screening of the spine and dynamic computed tomography (CT) of the craniovertebral junction in patients with evidence of skeletal anomalies on plain X-ray. The extent of tonsillar herniation in relation to foramen magnum and atlas (C1) arch was meticulously measured in millimeter in all cases along with screening for syrinx. There was associated syrinx in 47 (64\%) cases ( - Fig. 1). The rostrocaudal extent and maximum diameter of syrinx were clearly documented on preoperative scans as a baseline for subsequent follow-up. The summary of radiologic findings is presented in (-Table $\mathbf{2}$ ).

Surgical management was standard foramen magnum decompression with $\mathrm{C} 1$ arch removal and partial axis (C2) laminectomy, depending on extent of tonsillar descent in all the cases (-Fig. 2). A wide pericranial graft was routinely harvested from occipital region in all the cases. Intradural manipulation was individualized in form of adhesiolysis (16\%) extrapial coagulation of tonsillar tip (13\%), and in early phase of study plugging of obex (4\%) was also performed. Augmentation duraplasty was done using either pericranial graft (83\%) or synthetic graft (8\%) (-Fig. 3). Fibrin glue reinforcement of suture line was done in $62 \%$ patients. Intervention for syrinx
Table 1 Presenting signs and symptoms of patients having Chiari malformation type I

\begin{tabular}{|l|l|l|}
\hline Signs and symptoms & No. of cases & $\%$ \\
\hline Suboccipital pain & 42 & 56 \\
\hline Weakness & 34 & 45 \\
\hline Hand atrophy & 26 & 35 \\
\hline Spasticity & 24 & 32 \\
\hline Hyperactive deep tendon reflexes & 32 & 43 \\
\hline Numbness ( $\geq 1$ limbs) & 32 & 43 \\
\hline Loss of temperature sensation & 30 & 39 \\
\hline Posterior column loss & 24 & 31 \\
\hline Facial numbness & 2 & 3 \\
\hline Unsteadiness & 30 & 40 \\
\hline Nystagmus & 35 & 47 \\
\hline Tinnitus & 5 & 7 \\
\hline Deafness & 2 & 3 \\
\hline Cerebellar signs & 20 & 27 \\
\hline Horner's sign & 5 & 6 \\
\hline
\end{tabular}

without craniovertebral decompression in form of syringostomy (two patients) and syringoplural shunt (two patients) was done in early phase of study. The surgical procedures performed are summarized in (-Table 3 ). The outcome analysis was based on postoperative clinical improvement and reduction in diameter of syrinx on postoperative MRI and categorized into improved, unchanged, or worsened.

\section{Results}

Out of 74 patients included in study, mean age was 28.8 years (range: 6-58 years). The majority of the included patients were in second or third decades (43\%), with male preponderance (55 males and 19 females). Average duration of symptoms clearly related to CM type I was 4.2 years (range: 2 months to 15 years). In our study, no definite pattern of progression in natural history of disease was noted. Most of the patients who were symptomatically stable for months to years presented with recent rapid progression. The most common symptom was suboccipital pain, brought on by neck movements or Valsalva's maneuver. Ten patients had headache as the only complaint, and one-half of the patients were initially labeled as functional. The most common finding included lower extremity weakness, hyperreflexia, and spasticity with atrophy in upper extremities (-Fig. 4). More than one-third of patients had sensory abnormalities in the form of decreased pain and temperature sensation in the upper limb and decreased proprioception in the lower limb. Nystagmus was present in 35 (47\%) patients, which was of downbeat type. Other cerebellar signs were present in 20 (27\%) patients and Horner's sign in $5(6 \%)$ patients. Cranial nerve involvement in form of facial numbness was present in two (3\%) patients, tinnitus in five (6\%), and deafness in two (3\%) patients.

On the basis of clinical presentation, patients were divided into three categories: foramen magnum compression 

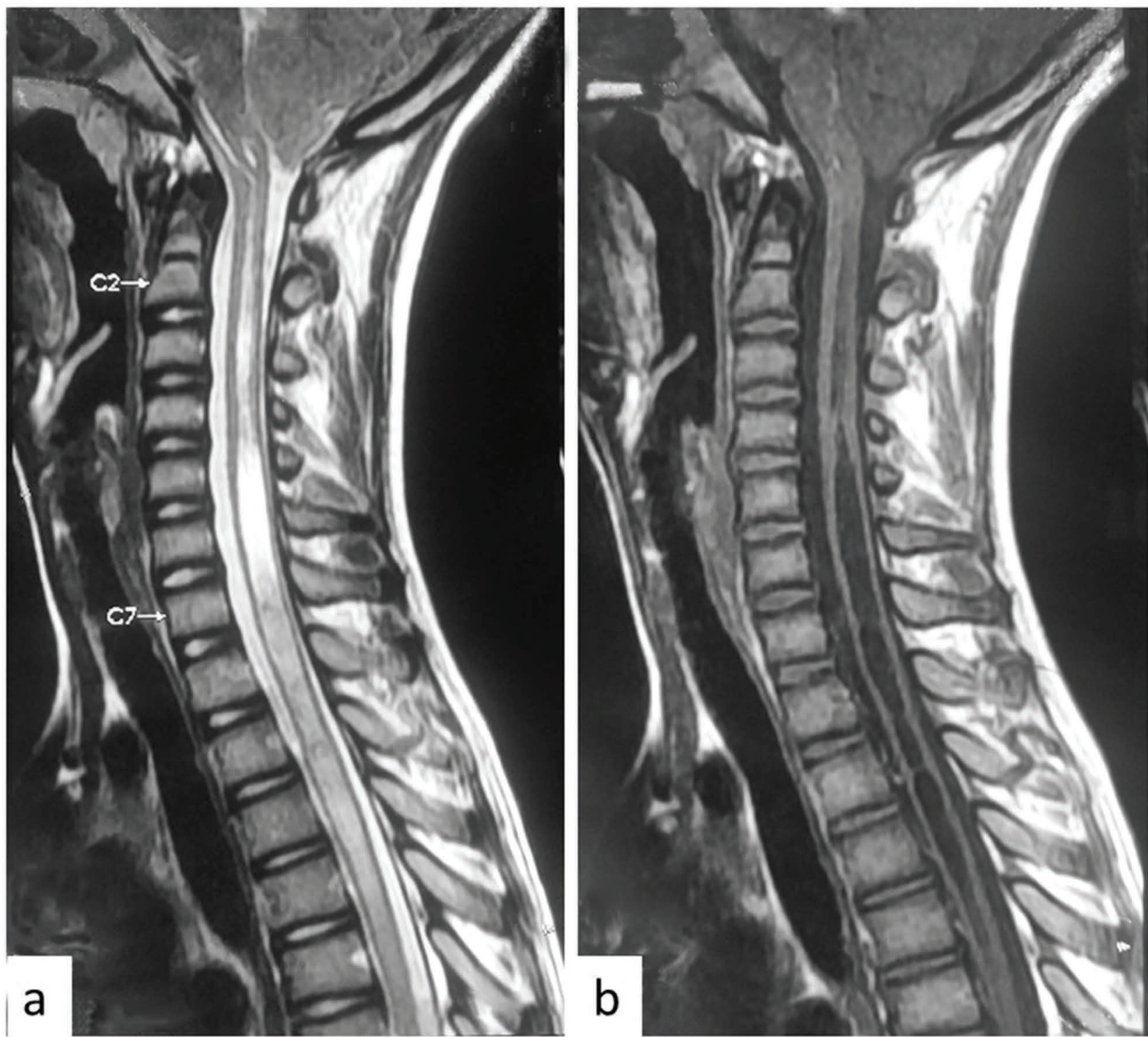

Fig. 1 Magnetic resonance imaging (MRI) of the spine showing Chiari malformation type I with syrinx formation in cervical cord in (a) T2- and (b) $\mathrm{T} 1$-weighted sequence.

Table 2 Radiologic details of Chiari malformation type I and associated bony anomalies

\begin{tabular}{|l|l|l|}
\hline Radiologic features & No. of cases & $\%$ \\
\hline Tonsillar herniation & & \\
\hline Foramen magnum & 5 & 6 \\
\hline C1 arch & 31 & 42 \\
\hline C2 lamina & 27 & 36 \\
\hline C3 lamina and below & 11 & 16 \\
\hline Skeletal anomalies & & \\
\hline Basilar invagination & 18 & 25 \\
\hline $\begin{array}{l}\text { Atlanto-occipital assimilation } \\
\text { Fused cervical vertebrae }\end{array}$ & 15 & 20 \\
\hline $\begin{array}{l}\text { Syringomyelia } \\
\text { (Cine-mode magnetic resonance } \\
\text { imaging) }\end{array}$ & 47 & 12 \\
\hline
\end{tabular}

syndrome (suboccipital pain, weakness, spasticity, hand atrophy, hyperactive deep tendon reflexes, facial numbness, and Horner's syndrome as predominant presenting features), central cord syndrome (dissociative sensory loss, segmental lower motor weakness in upper extremity, and long tract signs), and cerebellar syndrome (unsteadiness, nystagmus, and other cerebellar signs). Most patients in our study fall in the category of foramen magnum compression syndrome. MRI study showed tonsillar descent up to C1 arch in 31 (42\%) patients, C2 lamina in 27 (36\%), and subaxial spine (C3) or below in 11 (16\%) patients. The tonsillar descent was meticulously calculated in millimeter in all the cases. There was associated syringomyelia in 47 (64\%) patients, principally in the cervical cord. Entire rostrocaudal extent of syrinx was analyzed. Maximum diameter in millimeter was measured and documented as baseline for objective assessment of improvement in postoperative follow-up period. Associated bony anomalies such as basilar invagination, atlanto-occipital assimilation, 


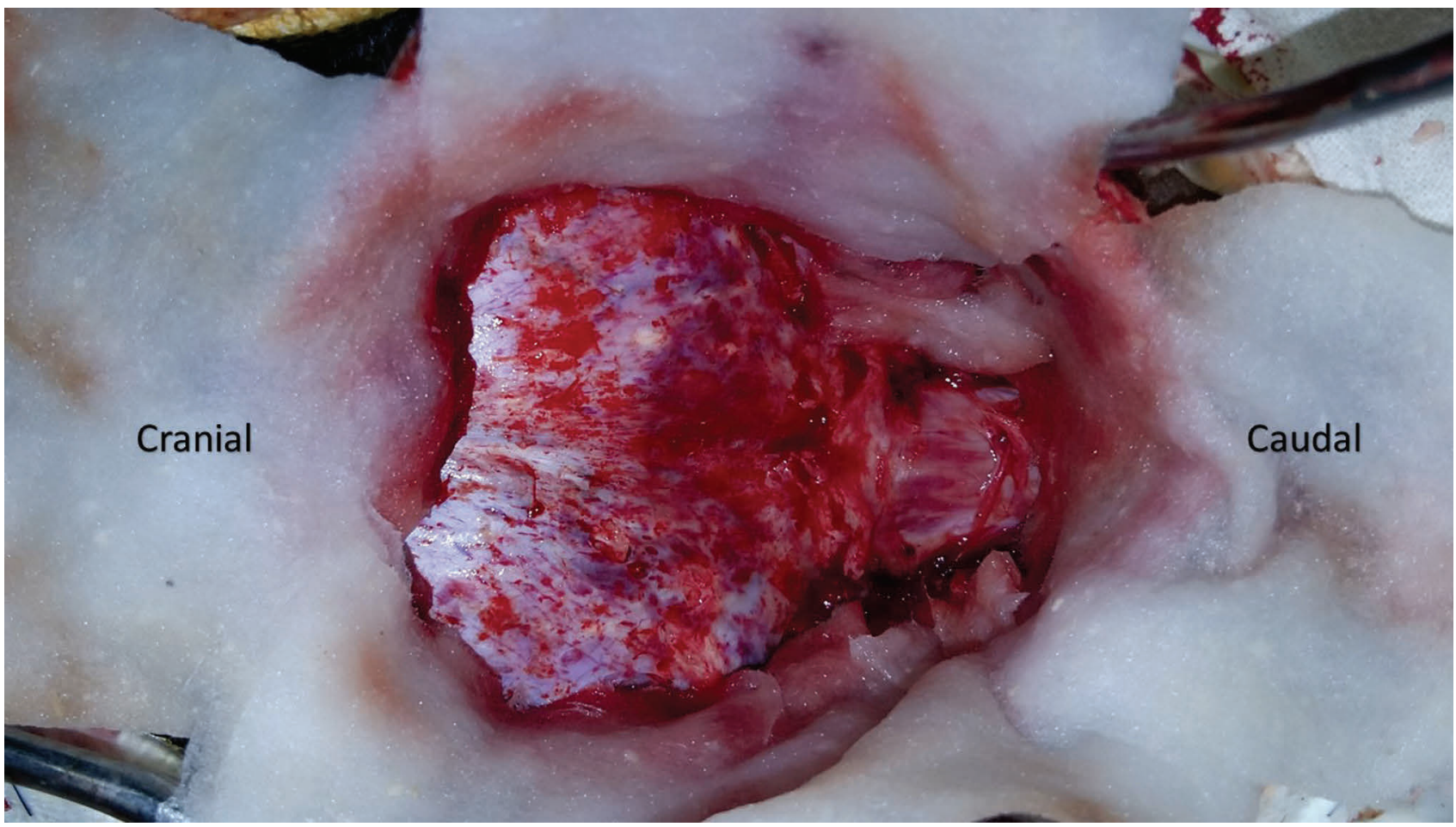

Fig. 2 Exposure after standard foramen magnum decompression, atlas posterior arch removal, and partial axis (C2) laminectomy, depending on extent of tonsillar descent in MRI of the spine.

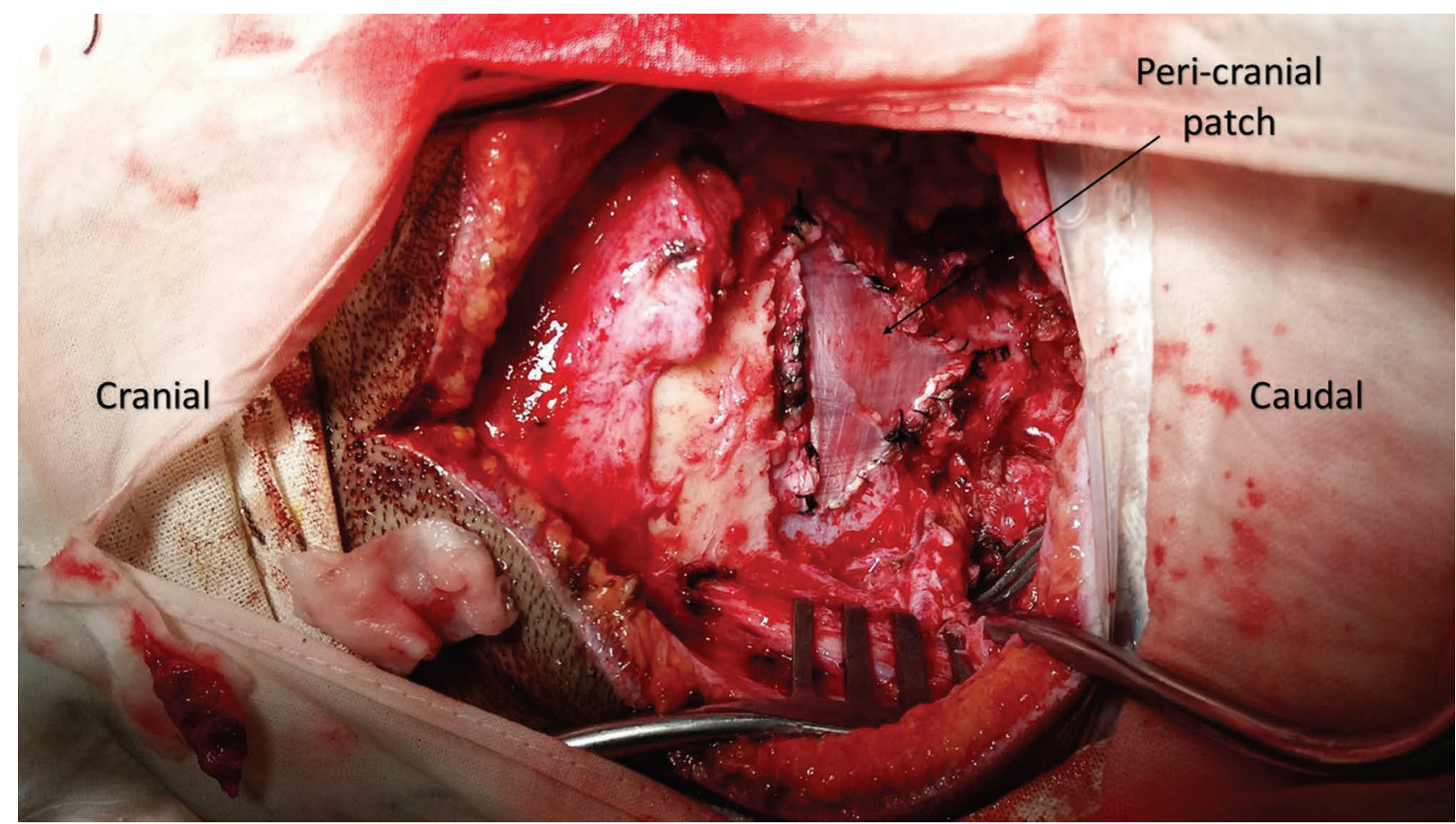

Fig. 3 Augmentation duraplasty using pericranial patch after bony bridge decompression.

and fusion of the cervical vertebrae were seen in 20 (27\%) patients. In all these subset of patients, dynamic CT of the craniovertebral junction was done to rule out atlantoaxial dislocation ( - Fig. 5a, b). Foramen magnum decompression with $\mathrm{C} 1$ arch removal and partial C2 laminectomy depending on extent of tonsillar descent was done in most patients. The extent of suboccipital craniectomy was up to medial margins of occipital condyles in the initial phase of this study, followed by suboccipital craniectomy limited to decompression of entire posterior surface of tonsils in the recent phase of 
this study (-Figs. 6, 7). The dense constrictive band causing intradural constriction was seen in 22 (30\%) patients in whom intradural exploration was done (-Figs. 6, 8). Adhesiolysis was done in 12 (16\%) patients. In severe tonsillar ectopia occluding the foramen of Magendie, extrapial coagulation of tonsillar tip was done in $10(13 \%)$ patients. In nine (12\%) patients, a thin membrane was found covering the obex that on piercing. free flow of CSF was established. In all cases of intradural manipulation, choroid plexus in the fourth ventricle was visualized, and free flow of CSF into subarachnoid space was ensured. In the early phase of this study, in three (4\%) patients, an occluding muscle plug was placed in dilated central canal at the obex to interrupt its hydrodynamic continuity with the fourth ventricle. This obex plugging procedure

Table 3 Surgical details

\begin{tabular}{|c|l|l|}
\hline Surgical Methods & No. of cases & $\%$ \\
\hline Foramen magnum decompression & & \\
\hline Suboccipital craniectomy & 70 & 95 \\
\hline C1 laminectomy & 42 & 55 \\
\hline C2 partial laminectomy & 15 & 20 \\
\hline Intradural exploration & & 16 \\
\hline Adhesiolysis & 12 & 13 \\
\hline $\begin{array}{c}\text { Extrapial coagulation of tonsillar } \\
\text { tips }\end{array}$ & 10 & 4 \\
\hline Plugging of obex & 3 & 83 \\
\hline Duraplasty & 64 & 8 \\
\hline Pericranial graft & 6 & 62 \\
\hline Synthetic graft & 48 & 3 \\
\hline Reinforcement by fibrin glue & & 3 \\
\hline Intervention for syrinx & 2 & \\
\hline Syringostomy & 2 & \\
\hline Syringoplural shunt & & \\
\hline
\end{tabular}
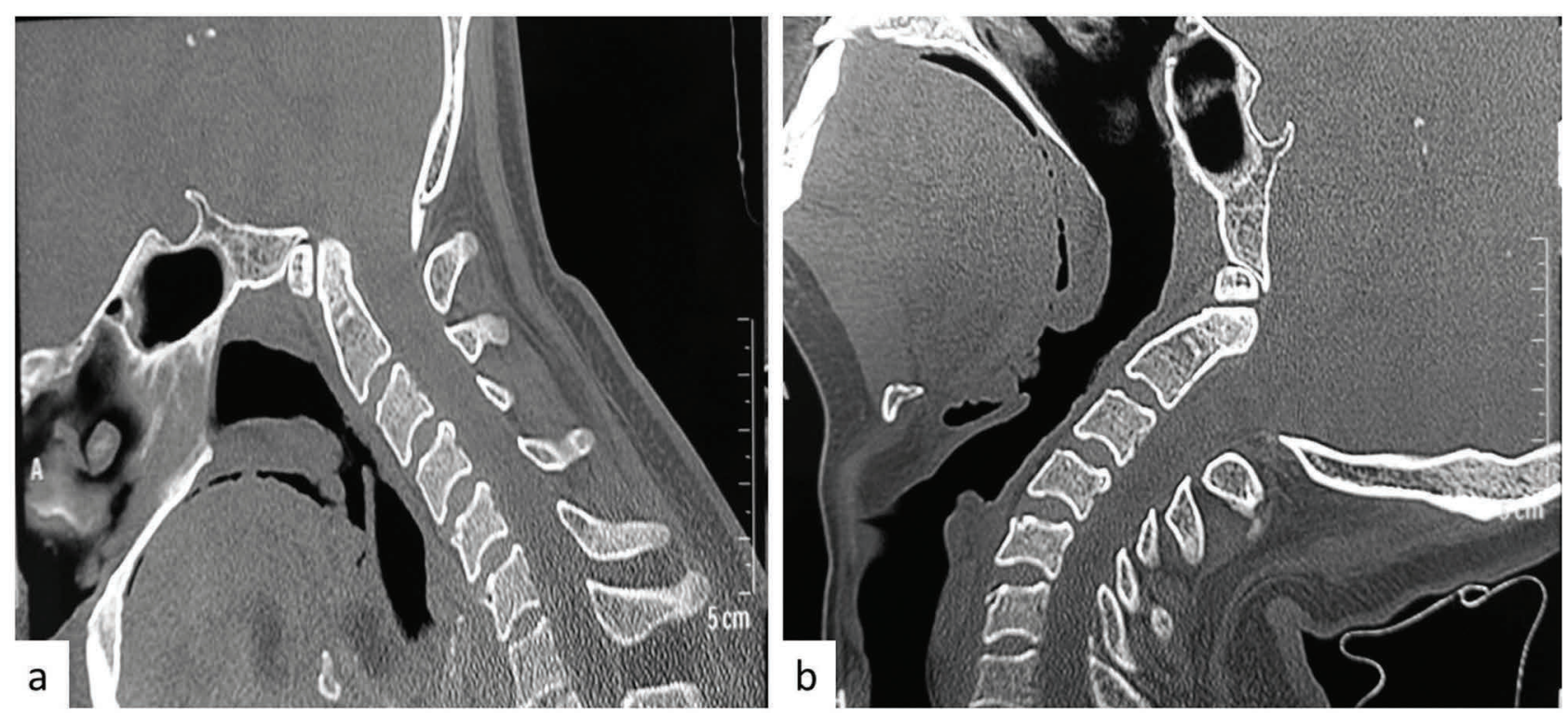

Fig. 5 (a, b) Dynamic computed tomography scan of craniovertebral junction to rule out bony instability in Chiari malformation type I with syrinx. was abandoned later due to more neurologic complications and change in concept of syrinx pathophysiology. Augmentation duraplasty with autologous pericranial graft was done in 64 (83\%) patients, and synthetic graft in 6 (8\%) patients. Reinforcement of suture line with fibrin glue was performed in 48 (62\%) patients. Intervention for syrinx was done in four (6\%) patients ( - Table 4). Postoperative complications included CSF leak in nine patients and wound infection in three patients, which were tackled with uneventful recovery. With the experience of previous decompressive procedures addressing to basic pathophysiology of CSF dynamics in syringomyelia, surgical strategy evolved from more aggressive approach into simpler and least invasive approach in the recent study. At 6-month follow-up, 42 patients had improvement, and 19 had stabilization in clinical course with worsening of symptoms seen in 13 patients (- Table 5). Significant improvement

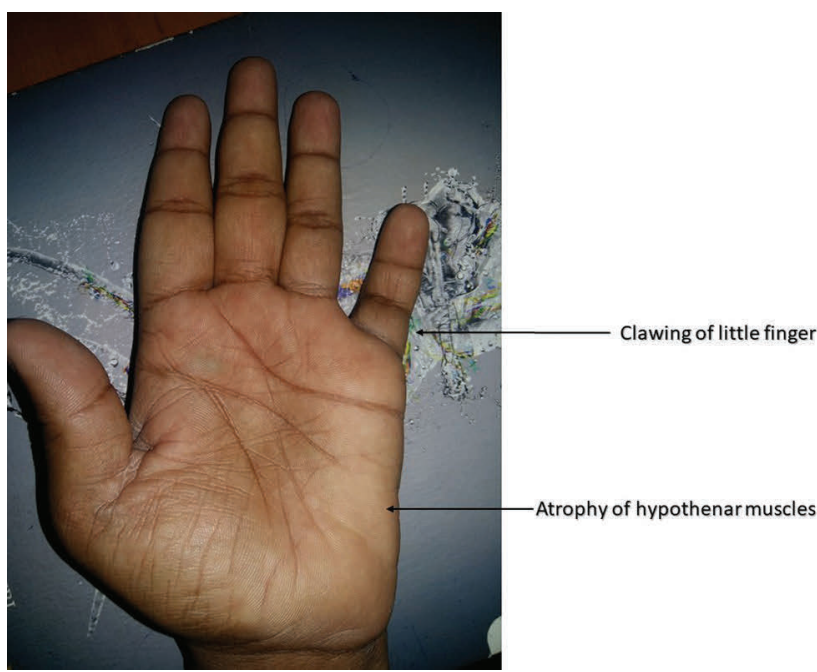

Fig. 4 Clinical photograph of hand muscle atrophy in Chiari malformation type I with syrinx. 


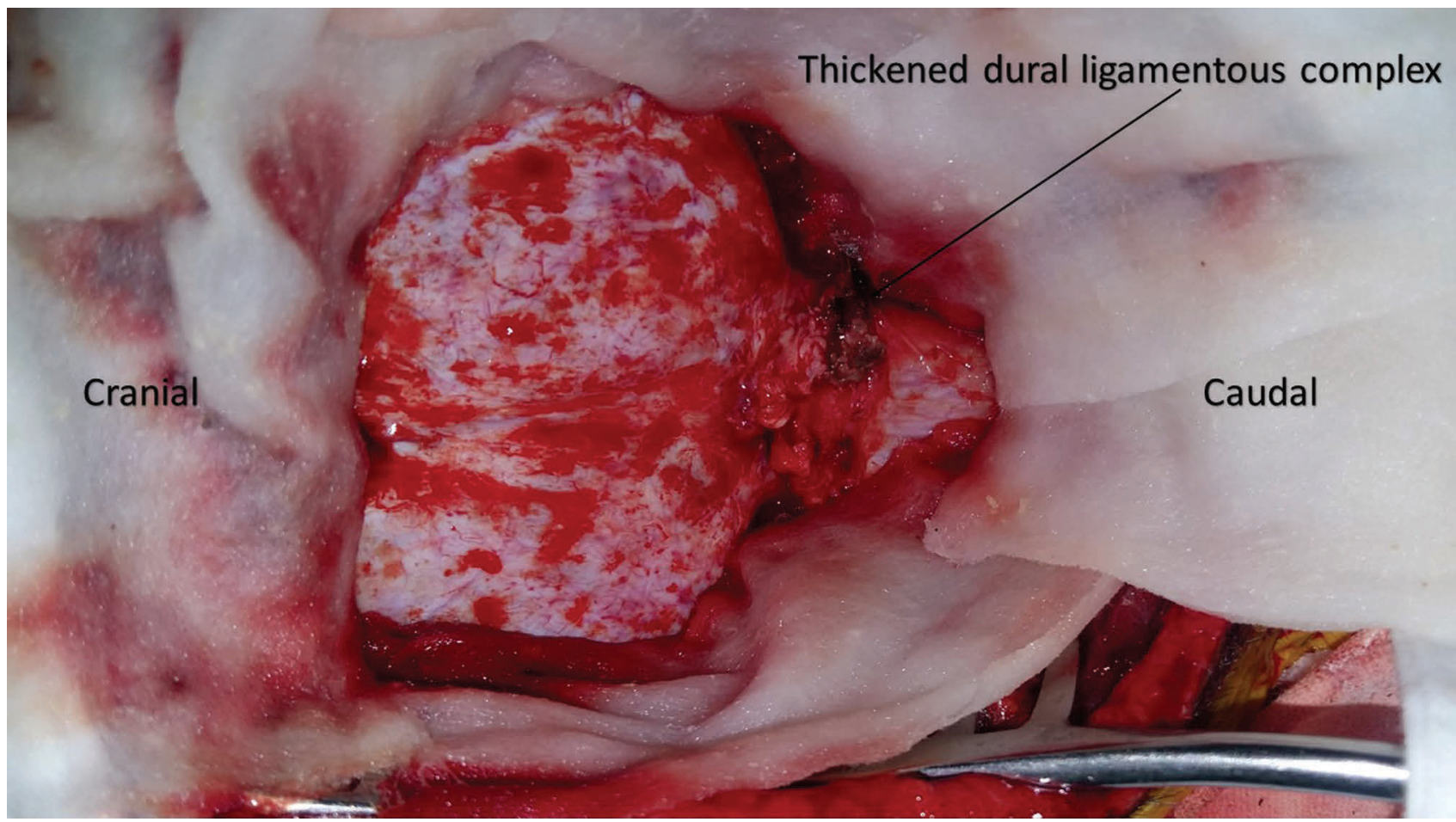

Fig. 6 Intraoperative image showing thickened dural ligamentous complex at the level of craniovertebral junction causing compression in Chiari malformation type I.

was seen in foramen magnum compression syndrome group. Follow-up MRI of the cervical spine in these patients showed marked reduction in syrinx size and well-decompressed foramen magnum with adequate CSF space around the cervicomedullary junction as compared with preoperative MRI (-Figs. 9, 10).

Many patients in our study who initially improved with surgery frequently returned to their presurgical state or sometimes even became worse and continued to deteriorate. Whether this denotes the natural course of the condition in a subset of this patient population is not known. In our study an attempt is done to overcome this bias by analyzing patients with CM type I who opted for conservative management as control group. This comparative analysis, unique in our study, is instrumental to ascertain the true benefits of surgery over what may be the natural history of this condition.

\section{Discussion}

The natural history of syringomyelia varies from spontaneous and complete regression to progressive neurologic deficits rightly described as "relentlessly progressive" by Lord Brain. ${ }^{1}$ The unpredictable clinical course of syringomyelia causes difficulties and controversies regarding management and continues to pose challenges. There is no currently clear consensus about the optimal therapy, and differing opinions are found in the literature. Another problem, encountered in interpreting the available information, is that a fairly long follow-up is required because syrinx progression may occur slowly over time. However, there is no effective nonsurgical alternative to operative decompression for patients with symptomatic
CM type I. The detailed understanding of the underlying pathophysiologic mechanisms is required to identify which patients will benefit most from posterior fossa decompression.

\section{Pathophysiologic Basis of Clinical Manifestations of Disease}

The CM type I consists of caudal displacement of cerebellar tonsils into the upper cervical canal, causing direct compression of the cerebellum or medulla at foramen magnum, which was the basis of suboccipital headache and neurologic signs and symptoms arising from the cerebellum and medulla. The full foramen magnum potentially compresses the herniated cerebellar tissue and restricts normal CSF flow across the craniovertebral junction, which increases the CSF movement in the spinal canal resulting in syrinx formation. The spinal cord damage starts centrally and spreads centrifugally to involve other spinal cord structures. Characteristically, the decussating fibers of spinothalamic tract conveying pain and temperature sensation are compromised initially. This results in loss of pain and temperature in "vest like" bilateral distribution with the preservation of soft touch sensation and proprioception, characteristically described as dissociation of sensory loss. With forward extension of disease process, the anterior horn cells become involved at the level of lesion resulting in segmental lower motor neuron weakness. Similarly lateral extension results in Horner's syndrome, and dorsal extension causes involvement of posterior column.

\section{Selection of Candidates for Surgery}

The likelihood of improvement of symptoms with surgery should influence the decision to recommend surgery. 


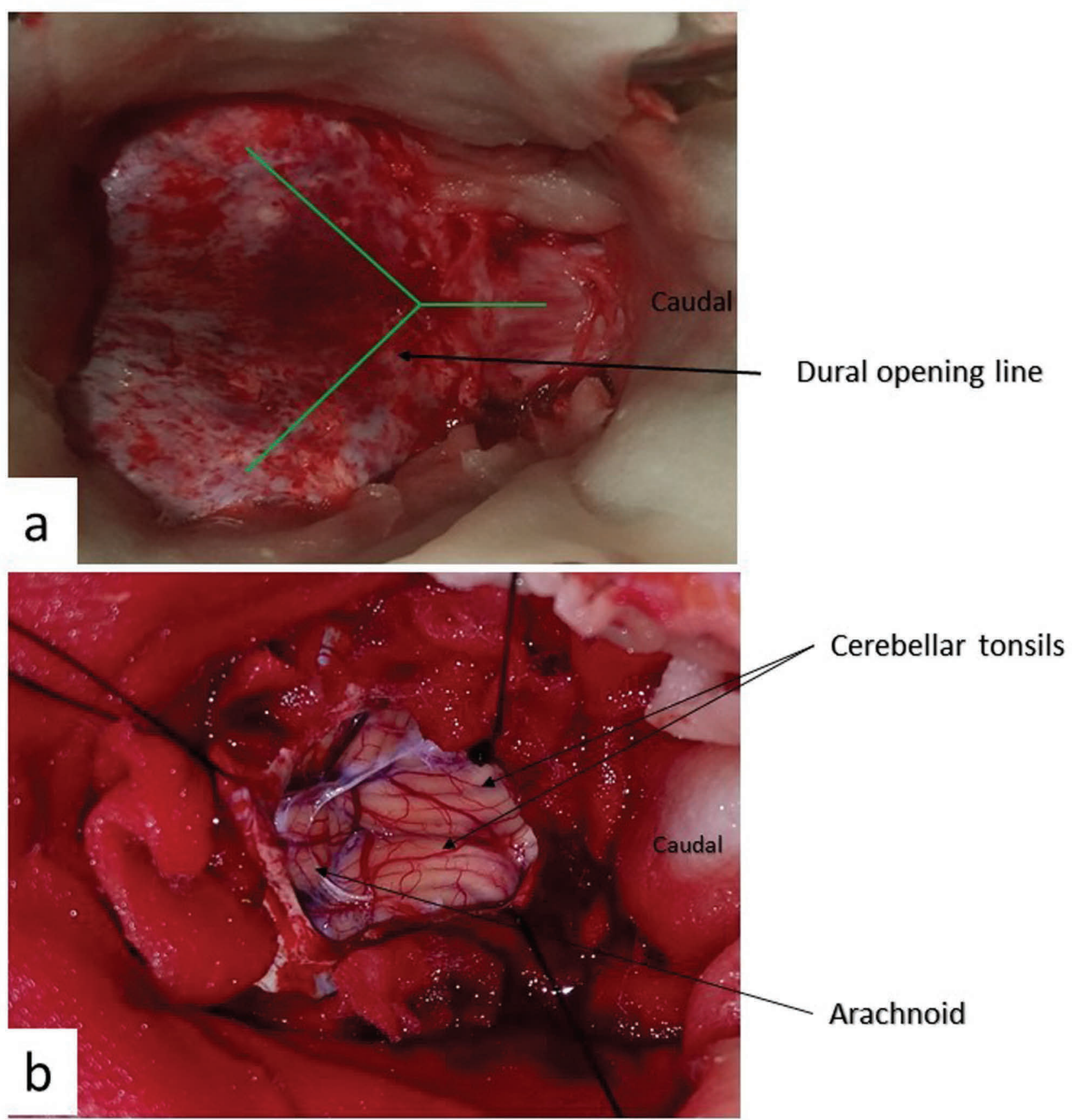

Fig. 7 Intraoperative images showing (a) dural incision line across the craniovertebral junction (in green) and (b) exposure of both tonsils beyond foramen magnum and arachnoid band for adhesiolysis.

All the clinical manifestations of syrinx associated with $\mathrm{CM}$ type I do not respond equally to surgery. However, early diagnosis and surgical treatment of syringomyelia are essential to arrest progressive myelopathy and prevent further loss of neurologic function. Many authors ${ }^{2}$ have recognized the prognostic value of certain clinical variables including clinical syndromes. Suboccipital headache caused by tonsillar impaction respond well to adequate decompressive therapy. Pyramidal tract manifestations and spinothalamic sensory loss improve as pressure of the cysts on these pathways is reduced. Weakness and atrophy of the hands show little improvement because of destruction of corresponding anterior horn cells. Similarly dysesthetic pain that is a form of denervation dysesthesia due to destruction of ascending spinal pathways with thalamic projection responds poorly to decompressive therapy. Each patient must be judged individually keeping in mind that progression of symptoms can sometimes occur rather abruptly. Because some of the neurologic deficits tend to become fixed once developed, most patients with Chiari and a distended syrinx must be candidates for surgery. CM presenting with lower cranial nerve involvement or symptoms of direct brainstem compression must also be candidates for surgery. ${ }^{3}$ 


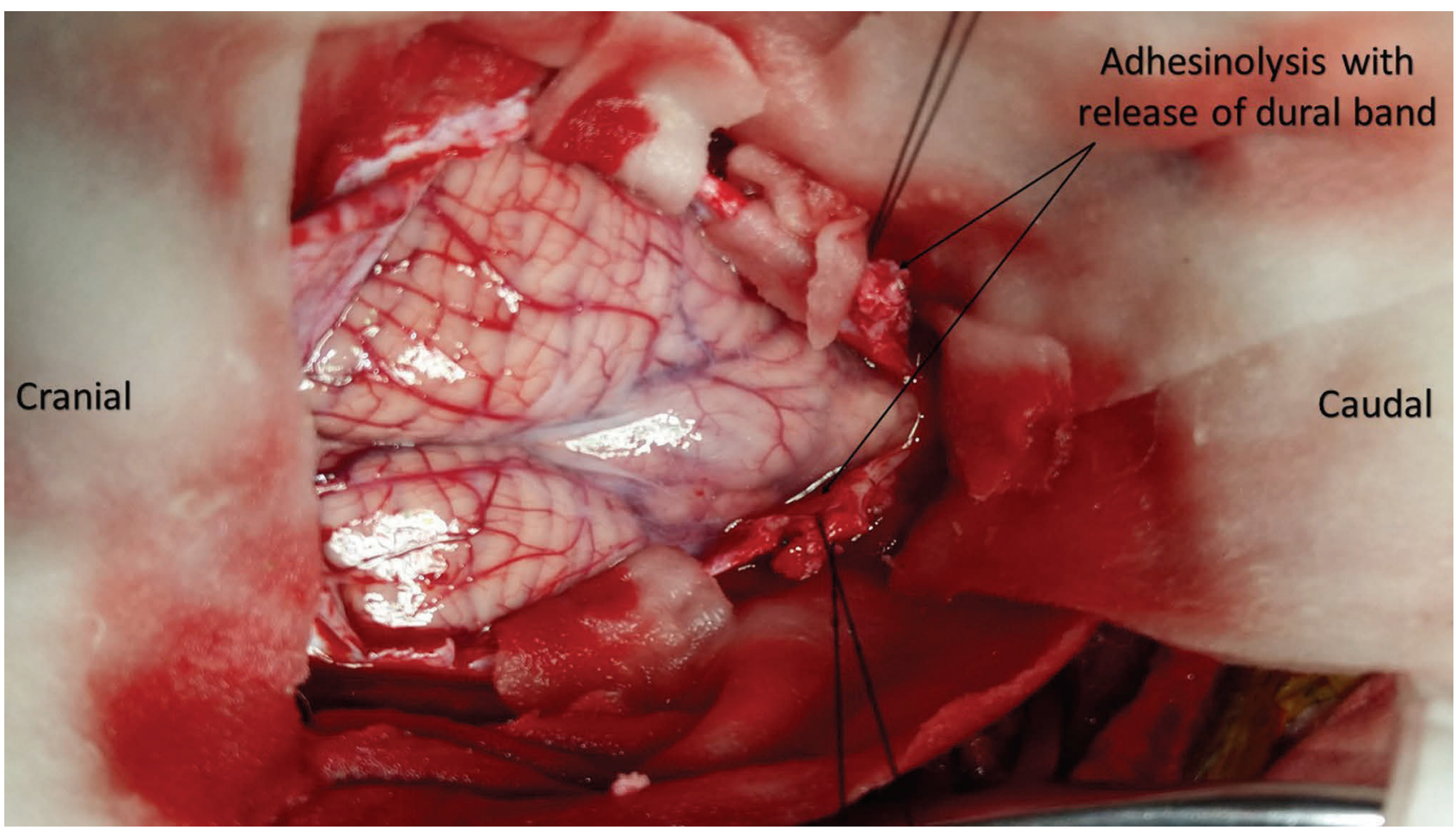

Fig. 8 Intraoperative image showing cutting of dural-ligamentous complex band at the level of craniovertebral junction.

Table 4 Surgical outcome at 6 months of follow-up

\begin{tabular}{|l|l|l|l|l|}
\hline Surgical procedure & Total & Better & Worse & No change \\
\hline 1. Foramen magnum decompression with duraplasty & 58 & 35 & 9 & 14 \\
\hline $\begin{array}{l}\text { 2. Foramen magnum decompression with intradural exploration and } \\
\text { duraplasty }\end{array}$ & 12 & 6 & 4 & 2 \\
\hline 3. Intervention for syrinx & 4 & 1 & 0 & 3 \\
\hline
\end{tabular}

Table 5 Outcome in long-term follow-up of 74 cases grouped in categories

\begin{tabular}{|l|l|l|l|}
\hline Outcome & Foramen magnum compression group & Central cord syndrome group & Cerebellar syndrome group \\
\hline Improved & 31 & 5 & 6 \\
\hline Unchanged & 3 & 12 & 4 \\
\hline Worse & 4 & 6 & 3 \\
\hline Total & 38 & 23 & 13 \\
\hline
\end{tabular}

\section{Surgical Techniques Followed, Its Correlation to Underlying Pathophysiologic Mechanisms and Recommendations}

Improved understanding of the pathophysiology of syringomyelia encourages the design and implementation of procedures directed toward eliminating the obstruction of CSF pathways, that is, strategies designed to reverse the pathophysiologic process underlying syringomyelia. The purpose of the operation is to enlarge the bony area of the craniocervical junction and expand the dura, surrounding the brainstem to effectively open the CSF pathways at the foramen magnum for providing effective and lasting treatment of syringomyelia with low morbidity. The specific surgical steps in this operation continue to undergo modification as surgeons attempt to identify the optimum treatment. This is usually dictated by patient characteristics and surgeons experience.
The management strategy follows a "top down" rule. ${ }^{4}$ Treatment always begins by addressing hydrocephalus, if it is present. A ventriculoperitoneal shunt placed in patients with hydrocephalus may relieve both cerebellar ectopia and dilatation of the central canal as well. In 1950, Gardner and Goodall at the Cleveland Clinic recognized the association of the CM type I with syringomyelia. ${ }^{5}$ They postulated that the outlets of the fourth ventricle were occluded by the CM type I and that a water-hammer pulsation was directed from the fourth ventricle, through the obex and into the central canal of spinal cord, leading to pulsatile expansion of the central canal to form the syrinx. To reverse this process, Gardner performed the surgical procedure that removed the bone from the posterior aspect of the foramen magnum, opened the fourth ventricle to the subarachnoid space, and plugged the obex..$^{5}$ In the 1970 Logue introduced a less invasive alternative 


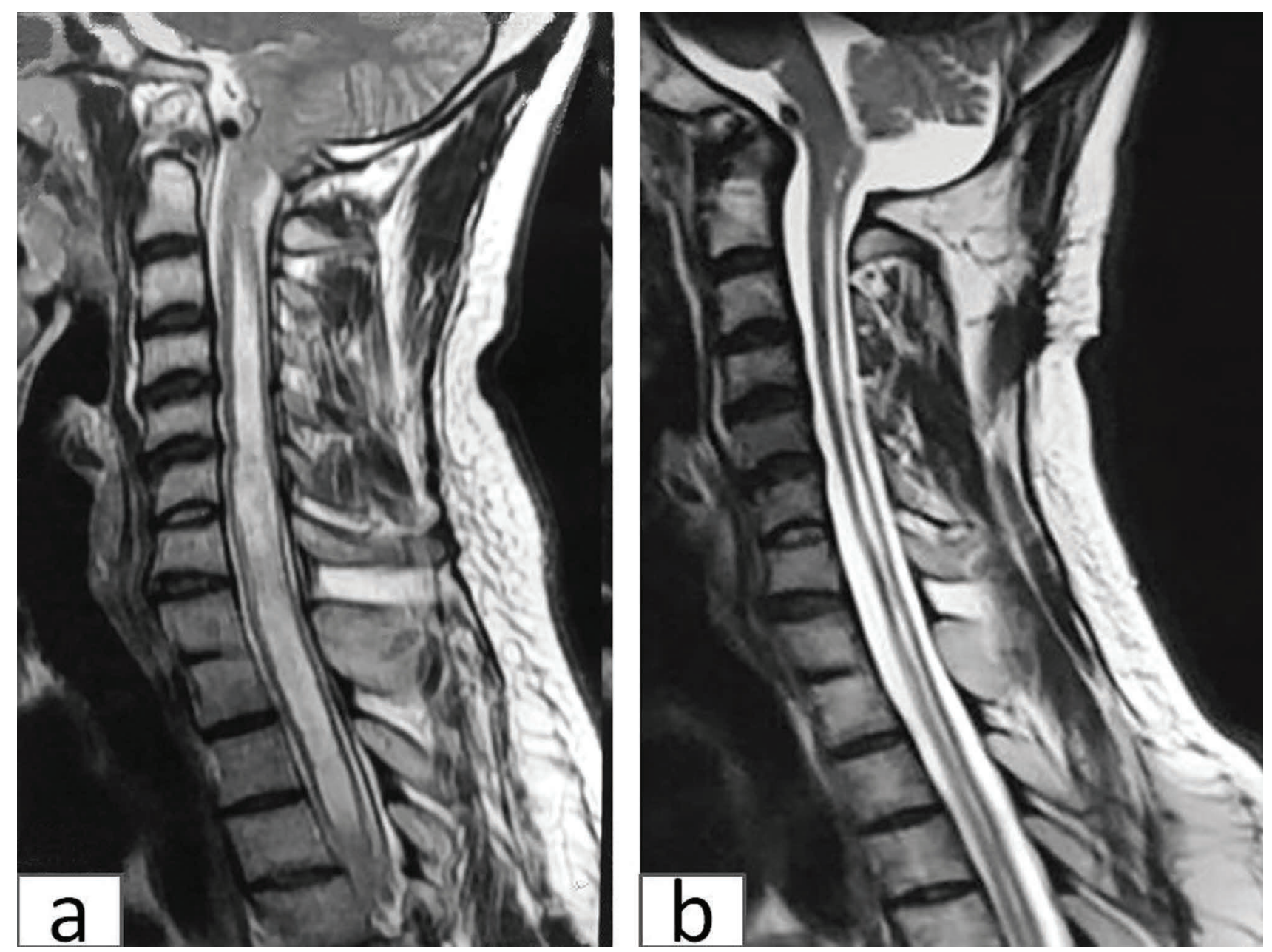

Fig. 9 Comparative MRI sagittal image of the cervical spine. (a) Preoperative and (b) follow-up at 6 months showing adequate foramen magnum decompression and continuation of craniospinal CSF space all around the cervicomedullary junction as well as marked reduction in syrinx diameter size.

to Gardner's procedure. ${ }^{6}$ His procedure consisted of simple bony decompression and expansion of the dura with tissue graft and avoidance of opening of the arachnoid membrane and entrance into the subarachnoid space or fourth ventricle. His group performed a clinical study comparing Gardner's procedure with their procedure of simple decompression and duraplasty and demonstrated that there was no difference in syrinx resolution between the procedures, although the Gardner's operation resulted in higher complication rate. ${ }^{6}$ Therefore, simple and least invasive craniocervical decompression and duraplasty without opening arachnoid membrane that eliminates the pathophysiologic mechanisms of syringomyelia was preferred in most of the cases in the later phase of our study.

A wide triangular pericranial graft harvested from the occipital region at the beginning of procedure was our standard institutional practice. The foramen magnum and arch of axis was exposed in the entire width of the dura, and more lateral exposure was avoided due to risk of vascular injury. It was our institutional preference to preserve muscle attachments and lamina of C2 intact to minimize postoperative pain and instability with the exception of 11 cases in which tonsillar descent was below $\mathrm{C} 2$. There is controversy regarding the extent of decompression required to alleviate symptoms. The importance to find answer to question "how much is enough" in our study is magnified in patients with CM type I because a significant proportion of these patients have small posterior fossa volume. Data analysis in the initial phase of this study revealed greater belief in wider foramen magnum decompression even up to extent of partial resection of medial margins of occipital condyles. The distance between the midpoints of the condyles is approximately $4.5 \mathrm{~cm} .{ }^{7}$ Resection of occipital condyles results in overt instability. In experimental studies when $50 \%$ of a condyle was resected, the range of motion was found to be increased by $153 \%$ during flexion extension, by $40.8 \%$ during lateral bending, and by $28.1 \%$ during axial rotation. Condylectomy was also associated with an increase in rotation at C1-C2, although not significantly when less than $75 \%$ of the condyle was resected. ${ }^{8}$ Apart from craniovertebral instability, oversize craniectomy can result in cerebellar ptosis due to herniation of tonsils and vermis with resultant adherence to overlying graft leading again to obstruction of CSF flow and reappearance of syringomyelia. Samii and Klekamp ${ }^{9}$ have advised that the size of the craniectomy should be limited to the width of the spinal canal and not to extend further 

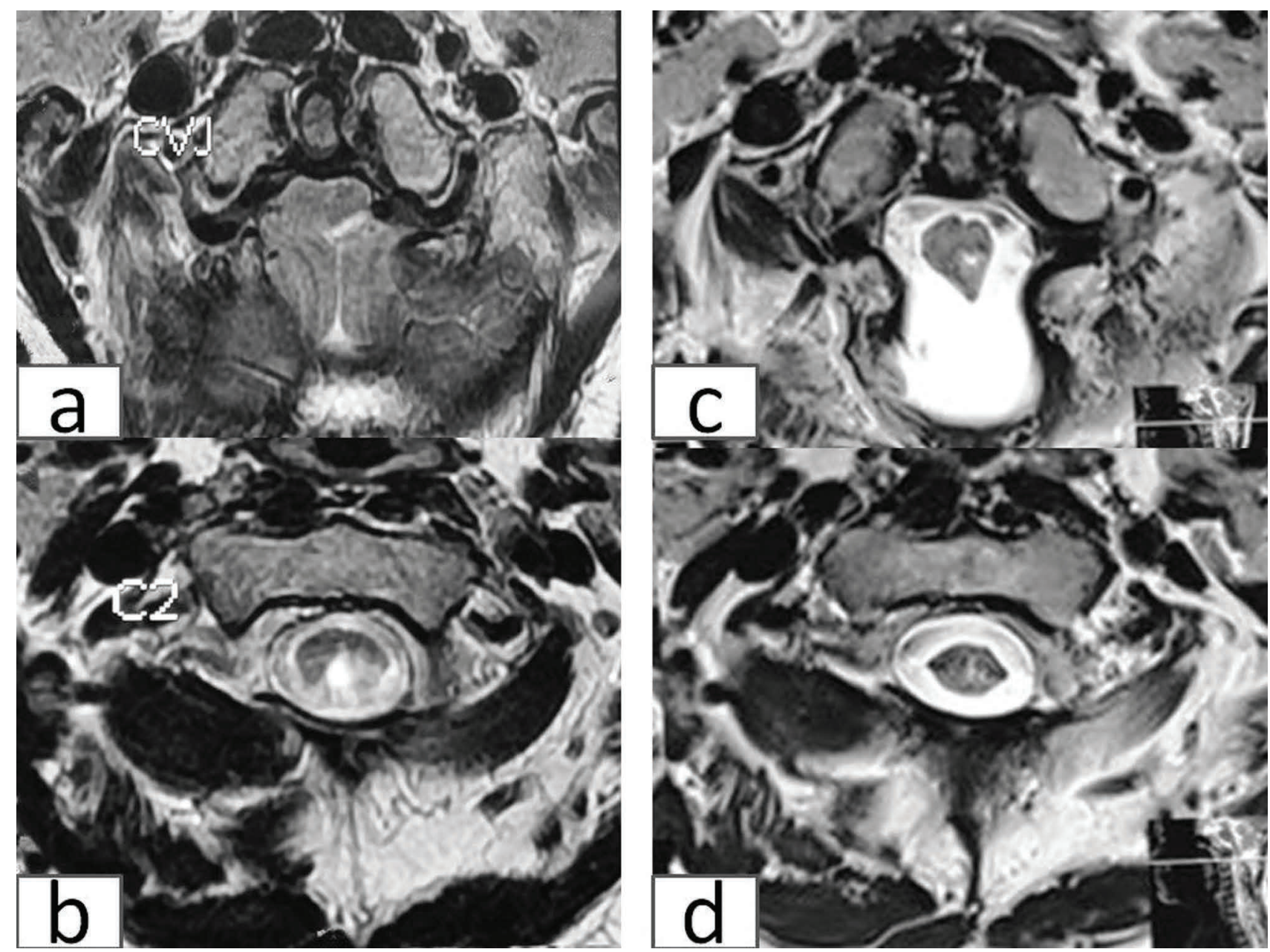

Fig. 10 Comparative MRI axial image of the cervical spine. (a, b) Preoperative and (c, d) follow-up at 6 months showing adequate foramen magnum decompression and continuation of craniospinal CSF space all around the cervicomedullary junction as well as marked reduction in syrinx diameter size.

upward than $2 \mathrm{~cm}$ from the rim of the foramen magnum. There was no significant difference in outcome when more conservative approach of limited removal of the bone to completely decompress the entire posterior surface of the cerebellar tonsils was advocated. In this study, associated bony anomalies were present in 20 (27\%) patients in whom the occipital bone was considerably flattened with rostral tilt at the foramen magnum and assimilation of the arch of atlas. In patients with CM type I, the bones of the skull base often are underdeveloped in $25 \%$ cases, resulting in skeletal anomalies such as basilar invagination (25-50\%), Klippel-Feil syndrome (5-10\%), and atlanto-occipital assimilation (1-5\%) that results in reduced volume of posterior fossa. ${ }^{10}$ In all of those patients, our institutional preference was to do preoperative CT study of the craniocervical junction that was having important implications in operative strategy for bony decompression. Grabb et al have described the entity of ventral brainstem compression in pediatric and young adult patients with Chiari I malformations. ${ }^{11}$ They have observed ventral cervicomedullary encroachment by the odontoid and its investing tissues into the rostral spinal canal resulting in flattening and distortion of the ventral brainstem in $28 \%$ of patients in their study. Significant ventral compression was defined as greater than $9 \mathrm{~mm}$ of reclination of the odontoid process from a line connecting the basion to the posterior aspect of the body of the axis. Their recommendation for patients with measurements of $9 \mathrm{~mm}$ or greater, is the reduction in ventral brainstem compression before posterior fossa decompression. In our subset of associated $25 \%$ basilar invagination, all have less than $9 \mathrm{~mm}$ of reclination of the odontoid process from a line connecting the basion to the posterior aspect of the body of the axis, so we have done only posterior decompression for CM with syrinx associated with basilar invagination.

Although conservative decompression was sufficient in most patients, few subsets of patients having thick dural band and significant tonsillar descent required intradural approach. Arachnoid adhesions are not directly visualized in conventional CT and MRI. However, preoperative cinewave MRI, intraoperative visualization of movements of tonsils seen through dura, and intraoperative ultrasound may help in deciding need for intradural approach. The dura was opened in midline at the $\mathrm{C} 1$ level with incision extended superiorly to split below foramen magnum to create Y-shaped dural opening. In all the cases in which intradural exploration was done, endpoint was visualizing 
choroid plexus of the fourth ventricle and free flow of CSF into subarachnoid space. In cases of severe tonsillar ectopia, extrapial coagulation of tonsillar tip was preferable to facilitate free flow of CSF from the foramen of Magendie. Capacious duraplasty using previously harvested pericranial graft with reinforcement of suture line using fibrin glue to prevent CSF leakage was our routine institutional practice. Older procedures of intervention for syrinx without bony decompression done in earlier part of our study were discontinued due to high recurrence rate and poor outcome. Overview of the literature about craniectomy size, C1 arch removal, duraplasty, and tonsillar resection and arachnoid dissection are listed in - Tables 6 to $\mathbf{9}$, respectively..$^{10,12-20}$

\section{Conclusion}

Chiari malformation type I presents a difficult challenge to neurosurgeons due to its unpredictable clinical course and controversies regarding management. Our understanding of managing this entity is still evolving, but innovative surgical techniques for breaking barriers of CSF flow to restore normal CSF dynamics across the craniocervical junction provide the pragmatic solution. The trend is toward balance

Table 6 Literature overview related to craniectomy size in Chiari malformation type I

\begin{tabular}{|c|c|c|c|}
\hline Author & No. of patients & Children/Adults & Extent of bone removal \\
\hline Erdogan et al $(2010)^{10}$ & 27 & Both & $\begin{array}{l}\text { Decompressive suboccipital craniectomy, at least } 3 \mathrm{~cm} \\
\text { above foramen magnum, width of } 3 \mathrm{~cm}\end{array}$ \\
\hline Gurbuz et al (2015) ${ }^{12}$ & 39 & Both & $\begin{array}{l}\text { Decompressive suboccipital craniectomy, at least } 3 \mathrm{~cm} \\
\text { above foramen magnum, width of at least } 4 \mathrm{~cm}\end{array}$ \\
\hline Kennedy et al (2015) ${ }^{13}$ & 156 & Children & Suboccipital craniectomy \\
\hline Kumar et al $(2014)^{14}$ & 1 & Adult & Suboccipital craniectomy \\
\hline Mutchnick et al $(2010)^{15}$ & 121 & Both & Wide suboccipital craniectomy \\
\hline Rehman et al (2015) ${ }^{16}$ & 21 & Adult & Suboccipital craniectomy \\
\hline Furtado et al $(2011)^{17}$ & 20 & Children & $\begin{array}{l}\text { Midline suboccipital craniectomy, individualized } \\
\text { according to age }\end{array}$ \\
\hline $\begin{array}{l}\text { Hoffman and Souweidane } \\
(2008)^{18}\end{array}$ & 40 & Both & $\begin{array}{l}\text { Suboccipital decompression, superior extension of } \\
\sim 1.5-2 \mathrm{~cm} \text {, lateral extension to the lateral most as- } \\
\text { pect of the foramen magnum and cervical spinal canal }\end{array}$ \\
\hline
\end{tabular}

Table 7 Literature overview related to C1 arch removal in Chiari malformation type I

\begin{tabular}{|c|c|c|c|}
\hline Author & No. of patients & Children/Adults & C1 arch removal \\
\hline Erdogan et al $(2010)^{10}$ & 27 & Both & $\begin{array}{l}\text { Total C1 laminectomy (removal of the atlantooc- } \\
\text { cipital ligament and dural scarring or bands on } \\
\text { the dura outside) }\end{array}$ \\
\hline Gurbuz et al $(2015)^{12}$ & 39 & Both & Total C1 laminectomy \\
\hline Kennedy et al $(2015)^{13}$ & 156 & Children & $\begin{array}{l}\text { Total C1 laminectomy and incision of the atlan- } \\
\text { tooccipital ligament in all cases; additional C } 2 \\
\text { partial laminectomy in } 12 \text { cases }\end{array}$ \\
\hline Kumar et al $(2014)^{14}$ & 1 & Adult & C1 laminectomy ( $3 \mathrm{~cm}$ wide) \\
\hline Mutchnick et al $(2010)^{15}$ & 121 & Both & $\begin{array}{l}\text { Total C1 laminectomy and careful resection of } \\
\text { dural bands }\end{array}$ \\
\hline Rehman et al $(2015)^{16}$ & 21 & Adult & $\begin{array}{l}\text { C1 laminectomy in all cases, additional C2 lami- } \\
\text { nectomy in } 2 \text { cases }\end{array}$ \\
\hline Furtado et al (2011) ${ }^{17}$ & 20 & Children & $\begin{array}{l}\text { C1 laminectomy in all cases, additional C2 lami- } \\
\text { nectomy in } 1 \text { case }\end{array}$ \\
\hline $\begin{array}{l}\text { Hoffman and Souweidane } \\
(2008)^{18}\end{array}$ & 40 & Both & $\begin{array}{l}\text { Extent of cervical laminectomy determined by } \\
\text { degree of tonsillar descent }\end{array}$ \\
\hline
\end{tabular}


Table 8 Literature overview related to duraplasty in Chiari malformation type I

\begin{tabular}{|c|c|c|c|c|}
\hline Author & No. of patients & Children/Adults & Materials & Results \\
\hline Abla et al $(2010)^{19}$ & Review of literature & Both & $\begin{array}{l}\text { Autologous and } \\
\text { nonautologous }\end{array}$ & $\begin{array}{l}\text { Duraplasty essential be- } \\
\text { cause of creating a cisterna } \\
\text { magna where one was } \\
\text { not previously present; } \\
\text { no superiority of neither } \\
\text { autologous nor nonautolo- } \\
\text { gous graft; pericranium is } \\
\text { preferred if possible }\end{array}$ \\
\hline Erdogan et al $(2010)^{10}$ & $\begin{array}{l}n=27 \text { (15 FMD with du- } \\
\text { raplasty, } 12 \text { only FMD) }\end{array}$ & Both & $\begin{array}{l}\text { Y-shaped opening } \\
\text { and dural grafting } \\
\text { with cadaveric } \\
\text { dura }\end{array}$ & $\begin{array}{l}\text { No statistical postoperative } \\
\text { differences a dura opening } \\
\text { recommended in cases } \\
\text { of any suspicion about } \\
\text { maintaining CSF flow in the } \\
\text { posterior fossa }\end{array}$ \\
\hline Gurbuz et al (2015) & $\begin{array}{l}n=39 \text { (21 duraplasty, } 18 \\
\text { nonduraplasty) }\end{array}$ & Both & n.m. & $\begin{array}{l}\text { No statistically significant } \\
\text { difference for surgical } \\
\text { results, but in regression of } \\
\text { postoperative syrinx size a } \\
\text { in patients with syrinx, ton- } \\
\text { sillar herniation }>10 \mathrm{~mm} \text {, } \\
\text { and symptom duration }<36 \\
\text { mo, duraplasty considered } \\
\text { to be a more reliable choice } \\
\text { despite a slightly higher } \\
\text { rate of complications }\end{array}$ \\
\hline $\begin{array}{l}\text { Hoffman and Souweidane } \\
(2008)^{18}\end{array}$ & $n=40$ & Both & $\begin{array}{l}\text { Autologous peric- } \\
\text { ranial tissue }\end{array}$ & $\begin{array}{l}\text { PFD with duraplasty is safe } \\
\text { and appropriate }\end{array}$ \\
\hline Kennedy et al (2015) ${ }^{13}$ & $n=156$ (nonduraplasty) & Children & n.m. & $\begin{array}{l}\text { Dura opening recommend- } \\
\text { ed for patients with rapid } \\
\text { progression of neurologic } \\
\text { deficits, scoliosis with syr- } \\
\text { inx, craniovertebral instabil- } \\
\text { ity requiring fusion, and if } \\
\text { preoperative MRI suggests } \\
\text { that partial C2 laminectomy } \\
\text { will be necessary }\end{array}$ \\
\hline Mutchnick et al $(2010)^{15}$ & $\begin{array}{l}n=121 \text { (56 nonduraplas- } \\
\text { ty, } 64 \text { duraplasty) }\end{array}$ & Both & $\begin{array}{l}\text { Y-shaped incision } \\
\text { extending caudal } \\
\text { past the foramen } \\
\text { magnum with a } \\
\text { generous pericra- } \\
\text { nial patch, covered } \\
\text { with Tisseel }\end{array}$ & $\begin{array}{l}\text { Clear benefits to most } \\
\text { children without duraplasty, } \\
\text { but recurrence is slightly } \\
\text { higher than with duraplasty }\end{array}$ \\
\hline Rehman et al $(2015)^{16}$ & $n=21$ & Adults & n.n. & $\begin{array}{l}\text { PFD with duraplasty best } \\
\text { treatment option }\end{array}$ \\
\hline Furtado et al (2011) ${ }^{17}$ & $n=20$ & Children & $\begin{array}{l}\text { With pericranium } \\
\text { or artificial dura }\end{array}$ & $\begin{array}{l}\text { PDF with duraplasty } \\
\text { preferred }\end{array}$ \\
\hline
\end{tabular}

Abbreviations: CSF, cerebrospinal fluid; FMD, foramen magnum decompression; MRI, magnetic resonance imaging; n.m., not mentioned; PFD, posterior fossa decompression. 
Table 9 Literature overview related to tonsillar resection and arachnoid dissection in Chiari malformation type I

\begin{tabular}{|l|l|l|l|}
\hline Author & $\begin{array}{l}\text { No. of } \\
\text { patients }\end{array}$ & Children/Adults & Intervention done \\
\hline Erdogan et al $(2010)^{10}$ & 27 & Both & $\begin{array}{l}\text { Opening of thick arachnoid layers and resection of thick arachnoid } \\
\text { bands between the tonsils can be necessary to obtain CSF passage }\end{array}$ \\
\hline Furtado et al $(2011)^{17}$ & 20 & $\begin{array}{l}\text { Children } \\
\text { Dense subarachnoid bands were released, and tonsils were shrunk } \\
\text { with bipolar cautery until free egress of CSF was seen from the } \\
\text { foramen of Magendie }\end{array}$ \\
\hline Guyotat et al $(1998)^{20}$ & 75 & Both & $\begin{array}{l}\text { Better outcome in patients treated by PFD and additional tonsil } \\
\text { resection }\end{array}$ \\
\hline
\end{tabular}

Abbreviations: CSF, cerebrospinal fluid; PFD, posterior fossa decompression.

between maximum decompression and preserving normal integrity.

\section{Informed Consent}

Informed consent was obtained from all individual participants included in this study.

\section{Declaration of Patient Consent}

The authors certify that they have obtained all appropriate patient consent forms. In the form, the patients have given their consent for their images and other clinical information to be reported in the journal. The patients understand that their names or initials will not be published and due effort will be made to conceal their identity, but anonymity cannot be guaranteed.

\section{Financial Support and Sponsorship \\ None.}

\section{Conflicts of Interest}

There are no conflicts of interest.

\section{References}

1 Brain WR. Brain's Diseases of the Nervous System. London, UK: Oxford University Press; 1970

2 Dyste GN, Menezes AH, VanGilder JC. Symptomatic Chiari malformations. An analysis of presentation, management, and long-term outcome. J Neurosurg 1989;71(2):159-168

3 Nair S, Menon G, Kachhara R, et al. Symptomatic adult Chiari malformation: operative strategies and surgical outcome. Progress in Clinical Neurosciences 1998;13:173-189

4 Rout D, Nair S. Neural anomalies at the craniovertebral junction and their management. Progress in Clinical Neurosciences 1989;4:257-275

5 Gardner WJ, Goodall RJ. The surgical treatment of ArnoldChiari malformation in adults; an explanation of its mechanism and importance of encephalography in diagnosis. J Neurosurg 1950;7(3):199-206

6 Logue V, Edwards MR. Syringomyelia and its surgical treatment-an analysis of 75 patients. J Neurol Neurosurg Psychiatry 1981;44(4):273-284

7 König SA, Goldammer A, Vitzthum HE. Anatomical data on the craniocervical junction and their correlation with degenerative changes in 30 cadaveric specimens. J Neurosurg Spine 2005;3(5):379-385
8 Vishteh AG, Crawford NR, Melton MS, Spetzler RF, Sonntag VK, Dickman CA. Stability of the craniovertebral junction after unilateral occipital condyle resection: a biomechanical study. J Neurosurg 1999;90(1 Suppl):91-98

9 Samii M, Klekamp J. Comments on the article Syringobulbia caused by delayed postoperative tethering of the cervical spinal cord: complication of foramen magnum decompression for Chiari malformation. Acta Neurochir (Wien) 1999;141:973

10 Erdogan E, Cansever T, Secer HI, Temiz C, Sirin S, Kabatas S, Gonul E. The evaluation of surgical treatment options in the Chiari malformation Type I. Turk Neurosurg 2010;20:303

11 Grabb PA, Mapstone TB, Oakes WJ. Ventral brain stem compression in pediatric and young adult patients with Chiari I malformations. Neurosurgery 1999;44(3):520-527, discussion 527-528

12 Gurbuz MS, Karaaslan N, Caliskan T, Unal E, Berkman MZ. Comparison of the surgical results for foramen magnum decompression with and without duraplasty in Chiari malformation type 1. Turk Neurosurg 2015;25(3):419-424

13 Kennedy BC, Kelly KM, Phan MQ et al. Outcomes after suboccipital decompression without dural opening in children with Chiari malformation type I. J Neurosurg Pediatr 2015;16(2):150-158

14 Kumar A, Bhattacharjee S, Sahu BP. Importance of C1 laminectomy in foramen magnum decompression surgery: a technical note. Asian J Neurosurg 2014;9(4):235

15 Mutchnick IS, Janjua RM, Moeller K, Moriarty TM. Decompression of Chiari malformation with and without duraplasty: morbidity versus recurrence. J Neurosurg Pediatr 2010;5(5):474-478

16 Rehman L, Akbar H, Bokhari I, Babar AKM, M Hashim AS, Arain SH. Posterior fossa decompression with duraplasty in Chiari-1 malformations. J Coll Physicians Surg Pak 2015;25(4):254-258

17 Furtado SV, Thakar S, Hegde AS. Correlation of functional outcome and natural history with clinicoradiological factors in surgically managed pediatric Chiari I malformation. Neurosurgery 2011;68(2):319-327, discussion 328

18 Hoffman CE, Souweidane MM. Cerebrospinal fluid-related complications with autologous duraplasty and arachnoid sparing in type I Chiari malformation. Neurosurgery 2008;62(3 Suppl 1):156-160, discussion 160-161

19 Abla AA, Link T, Fusco D, Wilson DA, Sonntag VK. Comparison of dural grafts in Chiari decompression surgery: review of the literature. J Craniovertebr Junction Spine 2010;1(1):29-37

20 Guyotat J, Bret P, Jouanneau E, Ricci AC, Lapras C. Syringomyelia associated with type I Chiari malformation. A 21-year retrospective study on 75 cases treated by foramen magnum decompression with a special emphasis on the value of tonsils resection. Acta Neurochir (Wien) 1998;140(8):745-754 